et al, 1997). Studies have shown that the prevalence of Alzheimer's disease in those with learning disability, especially Down's syndrome, is higher than in those with no learning disability (Patel et al, 1993).

The occurrence of Alzheimer-like neuropathology in Down's syndrome suggests that the genetic defect for familial Alzheimer's disease might reside on chromosome 21, which was, therefore, the first of the 22 autosomes to be tested using a genetic linkage strategy (McGuffin et al, 1994).

Dr Holmes's article was published among papers with the overall topic of old age psychiatry; early-onset Alzheimer's disease tends to fall within the remit of old age psychiatry except in those with Down's syndrome, who remain within learning disability services. From all the information I have gathered on Alzheimer's disease I have assumed that the clearest evidence for a genetic contribution to the aetiology of Alzheimer's disease is its association with Down's syndrome, which surely deserves a mention when discussing this specific area.

Holmes, C. (2002) Genotype and phenotype in Alzheimer's disease. British Journal of Psychiatry, 180 |3|-134.

Mann, D. M. A. (1988) Alzheimer's disease and Down's syndrome. Histopathology, 13, 125-127.

McGuffin, P., Owen, M. J., O’Donovan, M. C., et a (1994) Dementia. In Seminars in Psychiatric Genetics, pp. 192-206. London: Gaskell.

Patel, P., Goldberg, D. \& Moss, S. (1993) Psychiatric morbidity in older people with moderate and severe learning disability. II: The prevalence study. British Journal of Psychiatry, 163, 481-491.

Zigman, W., Schupf, N., Haveman, M., et al (1997) The epidemiology of Alzheimer's disease in mental retardation: results and recommendations from an international conference. Journal of Intellectual Disability Research, 4I, 76-80.

S. Shamas-Ud-Din Arundel House, Smithdown Health Park, Merseycare NHS Trust, Smithdown Road, Liverpool LI5 2LF, UK

Authors' reply: I thank Dr Shamas-Ud-Din for showing interest in my paper and would have to concur with the general criticism that Down's syndrome should have been mentioned. I would like to say, in my defence, that the article was written within the remit of 'advances in old age psychiatry'. A large number of old age psychiatric services see patients with Alzheimer's disease regardless of their age of onset and hence there was a need to cover some of the aspects of the genetics of early-onset Alzheimer's disease. However, I am unaware of any old age psychiatric service within the UK that routinely sees patients with Down's syndrome and Alzheimer's disease. This defence does not, however, excuse a restricted view that is damaging both to patient management and basic research.

Clearly, no patient should be excluded from expert dementia services because of their learning disability. In addition, there is much to learn about the genetic influences on the development of Alzheimer's disease in patients with Down's syndrome and on its clinical phenotype. Thus, as well as the effects of triplication of the amyloid precursor gene, the presence of the APOE $\varepsilon 4$ allele also appears to be associated with an increased risk of developing Alzheimer's disease (Deb et al, 2000). The effect of the presence of the APOE $\varepsilon 4$ allele on age of onset is still unclear but, unlike in those with no learning disability, the presence of APOE $\varepsilon 4$ appears to be associated with an earlier age of death (Hardy et al, 1994). At post-mortem the brain lesions and cholinergic losses seen in individuals with Down's syndrome are the same as those seen in both early- and late-onset Alzheimer's disease. However, despite these neuropathological findings, the evidence for the beneficial effects of cholinesterase inhibitors in patients with Down's syndrome and Alzheimer's disease is still largely anecdotal (Kishani et al, 1999). It is clear that the two specialities, old age psychiatry and learning disabilities, have much to learn from each other.

Deb, S., Braganza, J., Norton, N., et al (2000)

$A P O E \varepsilon 4$ influences the manifestations of Alzheimer's disease in adults with Down's syndrome. British Journal of Psychiatry, 176 468-472.

Hardy, J., Crook, R., Perry, R., et al (1994) Apo E genotype and Down's syndrome. Lancet, 343 979-980.

Kishani, P., Sullivan, J., Walter, B., et al (1999) Cholinergic therapy for Down's syndrome (letter). Lancet, 353, 1064-1065

C. Holmes Memory Assessment and

Research Centre, West Hampshire

NHS Trust, Moorgreen Hospital,

Botley Road,West End, Southampton

SO30 3JB, UK

\section{Clinical diagnosis of dementia with Lewy bodies}

It is clinically important to differentiate dementia with Lewy bodies (DLB) from other types of neurodegenerative dementias because of the prospect of better response to drugs such as cholinesterase inhibitors as well as the risk of development of neuroleptic sensitivity. However, usefulness of the commonly used definition of DLB (McKeith et al, 1996) remains to be established in community and primary care settings. The findings of the Islington study (Stevens et al, 2002) suggest that DLB is a clinically significant type of dementia in the community.

We had an opportunity to look at the prevalence of DLB in a small but representative community sample of patients meeting DSM-IV criteria for dementia (American Psychiatric Association, 1994) in Kerala, a southern state of India. These cases were identified using a novel casefinding method (Shaji et al, 2002). We identified 33 cases of dementia in the study area with a population of 1979 aged $>60$ years. A psychiatrist assessed all the subjects at their residence and assigned a DSM-IV diagnosis. Seventeen people with dementia $(52 \%)$ met criteria for Alzheimer's disease, 12 (36\%) were diagnosed as having vascular dementia, while in $4(12 \%)$ the dementia was felt to be secondary to other conditions such as chronic obstructive pulmonary disease, cardiac failure, Parkinson's disease and subdural haematoma. Three patients (9\%) met criteria for probable DLB and one $(3 \%)$ met criteria for possible DLB when the consensus criteria (McKeith et al, 1996) were applied. The combined prevalence of DLB was therefore $12 \%$. All these patients had earlier met the criteria for Alzheimer's disease as per DSM-IV.

On retrospective application of the separate 'clinical' diagnostic criteria used in the Islington study to our case records, only two of our patients met those criteria, reducing the proportion of patients with DLB to $6 \%$. This is strikingly similar to the figure reported in the Islington study. One limitation of these 'clinical' criteria is that they are too restrictive a definition of DLB. If visual hallucinations are indeed such an important diagnostic marker, then the consensus criteria themselves could be modified by making visual hallucinations an essential symptom for the diagnosis of 
DLB. We need to examine whether such modifications will improve the recognition of DLB in clinical practice.

American Psychiatric Association (1994) Diagnostic and Statistical Manual of Mental Disorders (4th edn) (DSM-4). Washington, DC: APA.
McKeith, I. G., Galasko, D., Kosaka, K., et al (1996) Consensus guidelines for the clinical and pathologic diagnosis of dementia with Lewy bodies (DLB): report of the consortium on DLB international workshop. Neurology, 47, III3-II24.

Shaji, K. S., Arun Kishore, N. R., Lal, K., et al (2002) Revealing a hidden problem. An evaluation of a community dementia case-finding program from the
Indian 10/66 dementia research network. International Journal of Geriatric Psychiatry, 17, 222-225.

Stevens, T., Livingston, G., Kitchen, G., et al (2002) Islington study of dementia subtypes in the community. British Journal of Psychiatry, 180, 270-276.

K. S. Shaji, T. lype, K. R. Anandan Medical College, Thrissur-680596, Kerala, India

\section{One hundred years ago}

\section{Verbal obsessions. By James Shaw, M.D., M.CH.R.U.I.}

MAGNAN defines an obsession as being a mode of cerebral activity in which a word, thought, or image rises into consciousness involuntarily and without discomfort when physiological, but forcibly and with painful persistence when pathological. Verbal obsessions are those in which isolated words - mostly obscene or blasphemous - constitute the morbid besetment. They should be distinguished from coprolalia, obscene speech; from the blasphematory mania of Verga, which he described as a special variety of obsession taking the form of oaths, blasphemies, or indecent utterances; and from the onomatomania of Charcot and Magnan, in which a word cannot be recollected without a painful searching of the memory, or a word or phrase is ever present in consciousness and must be emitted at intervals, its utterance being repressed for a short space only at the cost of extreme and constantly increasing mental pain. In my cases the besetting words were never uttered. The words differed from psychical or psychomotor hallucinations in that they were never spoken of as "voices in the head" nor as "voices" at all. Verbal obsessions may constitute the leading feature of a sort of obsessional aberration, as in the second case below, or an early symptom of a form of insanity, an obsessional melancholia, which appears to me to be as much an entity as hypochondriacal melancholia is. The first case exemplifies the induction of obsessional melancholia by verbal obsessions.

\section{REFERENCE}

Lancet, 9 August 1902, pp. 359-360.

Resarched by Henry Rollin, Emeritus Consultant Psychiatrist, Horton Hospital, Epsom, Surrey 